Supporting Information for:

\title{
Post-passivation of multication perovskite with rubidium butyrate
}

José Carlos Germino, ${ }^{1, \S}$ Rodrigo Szostak, ${ }^{1,2,}{ }^{\S}$ Silvia G. Motti, ${ }^{3}$ Raphael F. Moral, ${ }^{1}$ Paulo E. Marchezi, ${ }^{1}$ Heitor S. Seleghini, ${ }^{1}$ Luiz G. Bonato, ${ }^{1}$ Francineide Lopes de Araújo, ${ }^{1}$ Teresa D. Z. Atvars, ${ }^{1}$ Laura M. Herz, ${ }^{3}$ David Fenning, ${ }^{4}$ Anders Hagfeldt ${ }^{2}$ and Ana Flávia Nogueira ${ }^{1, *}$ $\S$ The authors contributed equally to this work

*Corresponding author: anafla@unicamp.br

${ }^{1}$ University of Campinas (UNICAMP), Laboratório de Nanotecnologia e Energia Solar, Chemistry Institute, Campinas, PO Box 6154, 13083-970, Brazil.

${ }^{2}$ Laboratory of Photomolecular Science, Institute of Chemical Sciences and Engineering, École Polytechnique Fédérale de Lausanne, 1015, Lausanne, Switzerland

${ }^{3}$ Department of Physics, University of Oxford, Clarendon Laboratory, Parks Road, Oxford OX1 3PU, United Kingdom.

${ }^{4}$ Department of Nanoengineering, University of California, San Diego, La Jolla, CA 92093, USA.

This supporting information contains experimental details concerning the materials, synthesis of $\mathrm{RbBu}$, preparations of perovskite and surface modification, structural and optical characterization methods, PSCs assembly and characterization method, theoretical calculations, additional characterization data, and supplementary texts 1,2 and 3 . 


\section{Experimental Details}

\section{Materials}

Lead iodide $\left(\mathrm{PbI}_{2}, 99.99 \%\right)$ and lead bromide $\left(\mathrm{PbBr}_{2}, 99.99 \%\right)$ were purchased from TCI America, 9211 N. Harborgate St., Portland, OR 97203, USA. Cesium iodide (CsI, 99.9 $\%)$, butyric acid $\left(\mathrm{BuCO}_{2} \mathrm{H}, 99 \%\right)$, rubidium iodide (RbI, 99.9\%), rubidium carbonate $\left(\mathrm{Rb}_{2} \mathrm{CO}_{3}, \quad 99.9 \%\right), \quad$ 4-terc-butylpyridine $\quad(\mathrm{tBP} ; \quad 98 \%), \quad$ Lithium bis(trifluoromethanesulfonyl)imide (LiTFSI; $99.95 \%$ ), and anhydrous solvents (dimethyl formamide - DMF, dimethyl sulfoxide - DMSO, ethanol - EtOH, acetonitrile - ACN, and chlorobenzene) were purchased from Sigma-Aldrich, São Paulo, Brazil. Isopropanol (IPA, 99.9\%) was purchased from Synth, Brazil-SP. Formamidinium iodide (FAI) and FTO coated glasses (TEC7) were supplied by GreatCell Solar LTD, Queanbeyan, Australia.

\section{Synthesis of the rubidium butyrate $(\mathrm{RbBu})$}

Rubidium carbonate $\left(\mathrm{Rb}_{2} \mathrm{CO}_{3} ; 1 \mathrm{mmol} ; 231 \mathrm{mg}\right)$ was added slowly in $2 \mathrm{~mL}$ of butyric acid $\left(\mathrm{BuCO}_{2} \mathrm{H} ; 21.8 \mathrm{mmol} ; 1.92 \mathrm{mg}\right)$ under constant stirring, and the resulting solution was heated at $\mathrm{T}=100^{\circ} \mathrm{C}$ until completion of the gas evolution. After cooling the solution, $10 \mathrm{~mL}$ of diethyl ether $\left(\mathrm{Et}_{2} \mathrm{O}\right)$ was added in order to precipitate the rubidium butyrate $(\mathrm{RbBu})$. The resulting solid was centrifuged, washed two times with $10 \mathrm{~mL}_{\text {of }} \mathrm{Et}_{2} \mathrm{O}$, dried under reduced pressure and stored at a dry and inert atmosphere.

\section{Preparation of Perovskite and Surface Modification with RbBu}

The mixed halide perovskite solution was obtained from the equivalent proportional weight of each precursor in the same glass flask, considering 9\% excess of $\mathrm{PbI}_{2}$ : $\mathrm{CsI}=51.9$ mg; FAI = $309.5 \mathrm{mg} ; \mathrm{PbI}_{2}=686.9 \mathrm{mg} ;$ and $\mathrm{PbBr}_{2}=187.2 \mathrm{mg}$. Finally, $2 \mathrm{~mL}$ of DMF:DMSO (4:1) was added and the resulting solution of $\mathrm{Cs}_{0.10} \mathrm{FA}_{0.90} \mathrm{~Pb}\left(\mathrm{I}_{0.83} \mathrm{Br}_{0.17}\right)_{3}$ was stirred overnight. The CsFAMA solution was prepared by a precursor solution containing FAI (1 M), $\mathrm{PbI}_{2}(1.1$ 
M), $\operatorname{MABr}(0.2 \mathrm{M}), \mathrm{PbBr}_{2}(0.2 \mathrm{M})$ in anhydrous DMF:DMSO 4:1 (v:v): This composition contains excess of $9 \%$ of $\mathrm{PbI}_{2} .5 \%$ of volume of CsI $1.5 \mathrm{M}$ stock solution in DMSO was added to previous perovskite solution.

The perovskite thin-films were obtained from two-steps, spin-coating deposition method. Firstly, $50 \mu \mathrm{L}$ of the perovskite solution was added in a clean glass subtract, and it started to spin at $1000 \mathrm{rpm}\left(2000 \mathrm{rpm} \mathrm{s}^{-1}\right)$ for $10 \mathrm{~s}$. The substrate was accelerated to 4000 rpm $\left(2000 \mathrm{rpm} \mathrm{s}^{-1}\right)$ for $30 \mathrm{~s}$. At the final $10 \mathrm{~s}, 200 \mu \mathrm{L}$ of the antisolvent (chlorobenzene) was added to the perovskite, forming a transparent-brown thin-film that was annealed in a hotplate at $100{ }^{\circ} \mathrm{C}$ for $30 \mathrm{~min}$ in a nitrogen-filled glovebox.

After the annealing, the thin-films were cooled to room temperature. The surface modification of the perovskite was done by single-step using $150 \mu \mathrm{L}$ of the $\mathrm{RbBu}$ solution $(1,5,10,50$ and $100 \mathrm{mM}$ in IPA - dried using $4 \AA$ molecular sieves $)$ in a similar way to the antisolvent deposition (4000 rpm in the last 10s). The resulting modified perovskite thinfilms were annealed at $100{ }^{\circ} \mathrm{C}$ for 5 minutes in a nitrogen-filled glovebox.

\section{Structural Characterizations}

The SEM images were obtained on a Thermo Fisher Scientific Quanta $^{\mathrm{TM}} 250$ FEGSEM at $10 \mathrm{kV}$, under high vacuum $\left(1.24 \times 10^{-4} \mathrm{~Pa}\right)$, magnitude of $10^{5} \mathrm{x}$ and with an EverhartThornley Detector (ETD). NMR-MAS spectra were collected in a Bruker Avance II+ 400 $\mathrm{MHz}(9.4 \mathrm{~T})$ spectrometer, with ${ }^{1} \mathrm{H}$ frequency of $400.13 \mathrm{MHz},{ }^{13} \mathrm{C}$ frequency of $100.61 \mathrm{MHz}$ and ${ }^{87} \mathrm{Rb}$ frequency of $130.92 \mathrm{MHz}$. The proton decoupled ${ }^{87} \mathrm{Rb}$ MAS spectrum was acquired with a $\pi / 20$ pulse, calibrated to solid rubidium iodine, resulting in a pulse length of $0.217 \mu$ s. The MAS spin rate was $15 \mathrm{kHz}$. Due to the small amount of rubidium in the sample, an interval between acquisitions of $2 \mathrm{~s}$ was used. For reference, TMS was used for ${ }^{13} \mathrm{C}$ and ${ }^{1} \mathrm{H}$, and for ${ }^{87} \mathrm{Rb}$ aqueous rubidium chloride was used. ${ }^{87} \mathrm{Rb}$ spectrum for the $100 \mathrm{mM} \mathrm{RbBu}$ 
modified LHP sample 241,276 scans were acquired, resulting in approximately 5.6 days of acquisition time. For the solid RbI precursor 128 scans were acquired, and for the $\mathrm{RbBu}$ 1,816 scans were acquired. ${ }^{13} \mathrm{C}$ spectrum with cross-polarization was obtained with a $\pi / 2$ pulse length of $2.5 \mu \mathrm{s}$ in the ${ }^{1} \mathrm{H}$, a contact time of $3 \mathrm{~ms}$, and $1 \mathrm{~s}$ between acquisitions. MAS spin rate was $10 \mathrm{kHz}$. The number of acquisitions for the 10-RbBu sample was 2,357 scans. ${ }^{1} \mathrm{H}$ spectrum was obtained with a $\mu / 2$ pulse length of $3.461 \mu \mathrm{s}$ in the ${ }^{1} \mathrm{H}$ and $1 \mathrm{~s}$ between acquisitions. MAS spin rate was $15 \mathrm{kHz}$. The number of acquisitions for the $100 \mathrm{mM} \mathrm{RbBu}$ sample was 8 scans. Grazing Incidence Wide Angle X-ray Scattering (GIWAXS) measurements were performed at XRD2 beamline at the Brazilian Synchrotron Light Laboratory (LNLS) with X-ray energy of $7 \mathrm{keV}$, using the Pilatus $300 \mathrm{~K}$ detector with 3 seconds of integration time. The incidence angle of the X-ray beam relative to the film surface was set at $3^{\circ}$. Each GIWAXS image was azimuthally integrated to obtain 1D X-ray diffraction patterns using pyFAI python libraries. The intensity was normalized by the storage ring current. X-ray Photoelectron Spectra (XPS) were acquired under a pressure of 10-9 $\mathrm{Pa}$ with a Scient Omicron ESCA+ spectrometer with a high-performance hemispheric analyzer (EA-125). The excitation source used was a monochromatic Al Ka (1486.6 eV) beam. The data was analyzed in CasaXPS, setting the $\mathrm{C} 1 \mathrm{~s}$ peak at $284.8 \mathrm{eV}$ as the reference for calibration.

\section{Optical Characterization}

Electronic absorption spectra of the perovskite thin-films and its modifications were acquired with a Hewlett-Packard 8452A diode array spectrophotometer. Steady-state photoluminescence (PL) spectra were recorded in an OceanOptics 2000+ USB spectrometer, using a Kimmon He:Cd CW laser $\left(\lambda_{\text {exc }}=442 \mathrm{~nm}\right.$; power $\left.=300 \mathrm{~W}\right)$. The emission ranges 
were recorded from $288 \mathrm{~nm}$ to $1039 \mathrm{~nm}$. The films were oriented in a front-face configuration at $22.5^{\circ}$ in order to minimize the Rayleigh light scattering of the excitation source.

\section{Charge Carrier Dynamics and Mobility Measurements}

The charge carrier dynamics of the pristine and its RbBu modified LHPs were recorded using time-correlated single-photon counting (TCSPC) in a Edinburg Analytical Instruments FL 900 spectrofluorometer with an MCP-PMT (Hamamatsu R3809U-50; 50 ps) with a PicoQuant LDH-D-C-440 pulsed diode laser operating at $\lambda_{\text {exc }}=440 \mathrm{~nm}$ (bandwidth of $5 \mathrm{~nm}$, pulsewidth $=80 \mathrm{ps} ; \mathrm{F}=9.7 \mathrm{~nJ} \mathrm{~cm}^{-2}$ ). The decay signals were collected at the maxima emission wavelength of each sample in a time scale of $2 \mu \mathrm{s}$. The instrument response was recorded using a Ludox sample.

Optical-Pump THz-Probe (OPTP) measurements were performed using a Spectra Physics Mai Tai-Ascend-Spitfire Pro Ti:Sapphire regenerative amplifier generating 35 fs pulses at a repetition rate of $5 \mathrm{kHz}$. The optical pump excitation was obtained by frequency doubling the $800 \mathrm{~nm}$ laser output through a BBO crystal, resulting in $400 \mathrm{~nm}$ pulses. THz probe pulses were generated by a spintronic emitter which was composed of 1:8nm of $\mathrm{Co}_{40} \mathrm{Fe}_{40} \mathrm{~B}_{20}$ sandwiched between $2 \mathrm{~nm}$ of Tungsten and $2 \mathrm{~nm}$ of Platinum, all supported by a quartz substrate. Detection of the THz pulses was performed using electro-optic sampling in a ZnTe crystal (0.2 mm (110)-ZnTe on $3 \mathrm{~mm}(100)-\mathrm{ZnTe})$. The sample, THz emitter and $\mathrm{THz}$ detector were held under vacuum $\left(<10^{-2}\right.$ mbar $)$ during the measurements. OPTP measurements reveal no fluence dependence of the charge-carrier mobilities in each sample, for variation of the fluence of the laser from 0.9 to $32.2 \mu \mathrm{J} \mathrm{cm}^{-2}$ (Figure S7 and S8), which indicates negligible contribution from nonlinear processes during the measurements at these experimental conditions. The effective mobilities were extracted from the differential 
transmission of the $\mathrm{THz}$ probe immediately after $\mathrm{t}=0$ according to the method previously reported in Wehrenfennig et al., Adv. Mater. 2014, 26, $1584 .^{1}$

\section{Perovskite Solar Cells (PSCs) Assemble}

FTO-coated glass substrates were cleaned using Hellmanex solution $(2 \% \mathrm{v} / \mathrm{v}$ in water) with a toothbrush. Sequentially, substrates were placed in an ultrasonic bath with Hellmanex solution for 30 min, washed with deionized water (Milli-Q®) and EtOH. Finally, they were sonicated with IPA for 15 min, rinsed with acetone, and dried with compress air. Further $\mathrm{O}_{3}(\mathrm{~g})$ plasma treatment was carried out for $10 \mathrm{~min}$. The $\mathrm{SnO}_{2}$ planar layer was deposited by spin-coating technique (3000 rpm; $\left.200 \mathrm{rpm} \mathrm{s}^{-1}\right)$ using an IPA solution of pentahydrate tin(IV) chloride $\left(\mathrm{SnCl}_{4} .5 \mathrm{H}_{2} \mathrm{O} ; 0.05 \mathrm{~mol} \mathrm{~L}^{-1}\right)$. They were placed in a hotplate $(\mathrm{T}$ $=100{ }^{\circ} \mathrm{C}$ ), heated to $180{ }^{\circ} \mathrm{C}$ for $1 \mathrm{~h}$, and then treated with ozone plasma once again. Then, the substrates were placed in a Glovebox filled with nitrogen and were used for deposition of the perovskite layer. The perovskite films were deposited using the solvent engineering method. ${ }^{35}$ Following a two steps procedure: $10 \mathrm{~s}$ at $1000 \mathrm{rpm}\left(200 \mathrm{rpm} \mathrm{s}^{-1}\right)$ and $30 \mathrm{~s}$ at 4000 rpm $\left(2000 \mathrm{rpm} \mathrm{s}^{-1}\right)$. The antisolvent was dripped onto the spinning substrate $15 \mathrm{~s}$ left to stop. The surface modifications were made in the same way that thin-films for optical and structural characterization. Then, the films were annealed at $100{ }^{\circ} \mathrm{C}$ for $30 \mathrm{~min}$. The hole transport material (HTM) was prepared by dissolution of 2,2',7,7'-tetrakis(N,N'-di-pmethoxyphenyl-amine)- 9,9'-spirobifluorene (spiro-OMeTAD), lithium bis(trifluoromethanesulfonyl)imide (Li-TFSI, 1.8M in acetonitrile), tert-butylpyridine (tBP) and $\operatorname{tris}(2-(1 \mathrm{H}-$ pyrazol-1-yl)-4-tert-

butylpyridine)cobalt(III)tri[bis(trifluoromethane)sulfonimide] $\quad(\mathrm{FK} 209, \quad 0.25 \mathrm{M} \quad$ in acetonitrile) in the proportion 1:3.3:0.5:0.05 in chlorobenzene. The HTM solution was spin coated dynamically on a rotating substrate at $4000 \mathrm{rpm}$. An $80 \mathrm{~nm}$-thick gold top electrode was deposited as a top contact electrode by thermal evaporation under high vacuum. 


\section{Photovoltaic performance measurements}

The solar cells were measured using a $450 \mathrm{~W}$ xenon light source (Oriel). The light intensity was calibrated with a Si photodiode equipped with an IR-cutoff filter (KG3, Schott) and it was recorded during each measurement. The current-voltage characteristics of the cells were obtained by applying an external voltage bias while measuring the current response with a digital source meter (Keithley 2400). The voltage scan rate was $10 \mathrm{mV} \mathrm{s}^{-1}$ and no device preconditioning were applied before starting the measurement. The cells were masked with a black meta mask limiting the active area to $0.158 \mathrm{~cm}^{2}$ and reducing the influence of the scattered light. The photocurrent density was scaled to $1000 \mathrm{~W} \mathrm{~m}^{-2}$.

Stability test of the solar cells was carried out under a full AM 1.5 Sun-equivalent white LED lamp and $\mathrm{N}_{2}(\mathrm{~g})$ flow. The device area was masked to around $0.16 \mathrm{~cm} 2$. The devices were measured at MPP tracking under continuous illumination. The MPP was updated every $10 \mathrm{~s}$. Every $15 \mathrm{~min}$. a J-V curve was recorded.

\section{Theoretical Calculations}

Geometry optimization and electrostatic surface of $\mathrm{Bu}^{-}$anion were performed under the DFT framework using density-functional B3LYP², using a triple-zeta Pople's basis-set with polarization and diffuse functions $\left(6-311++\mathrm{G}^{* *}\right)^{3-5}$ level. Calculations were done using the ORCA 4.2.1 ${ }^{6}$ and Avogadro ${ }^{7}$ visualization software. 
Additional Characterization Data

a

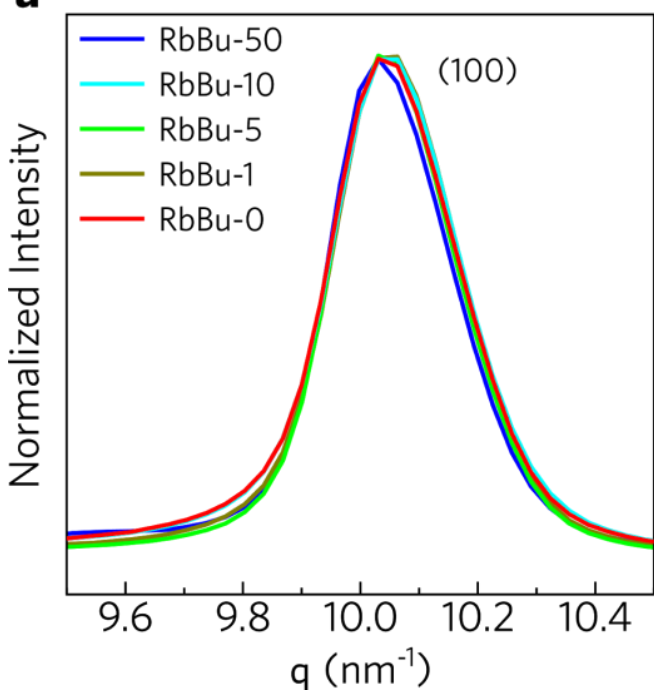

b

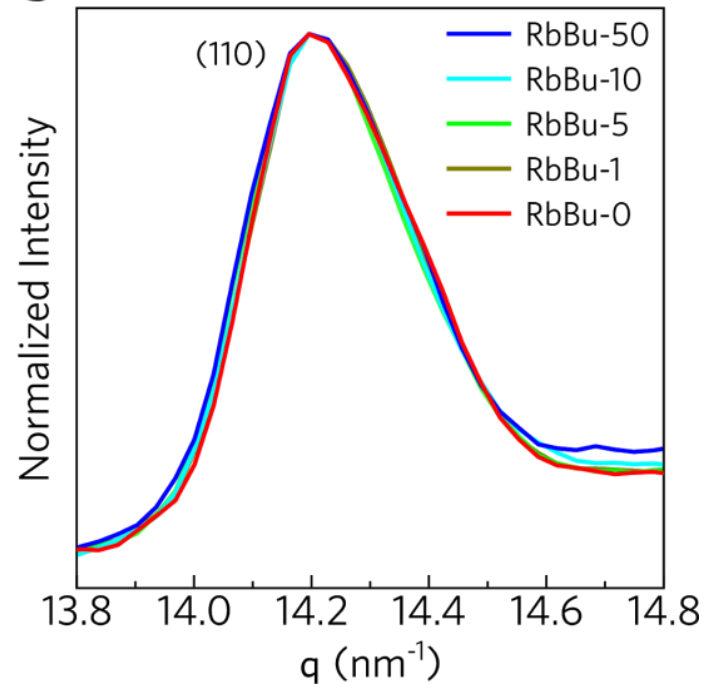

Figure S1. Zoom into the (a) (100) and (c) (110) peaks of the XRD patterns.

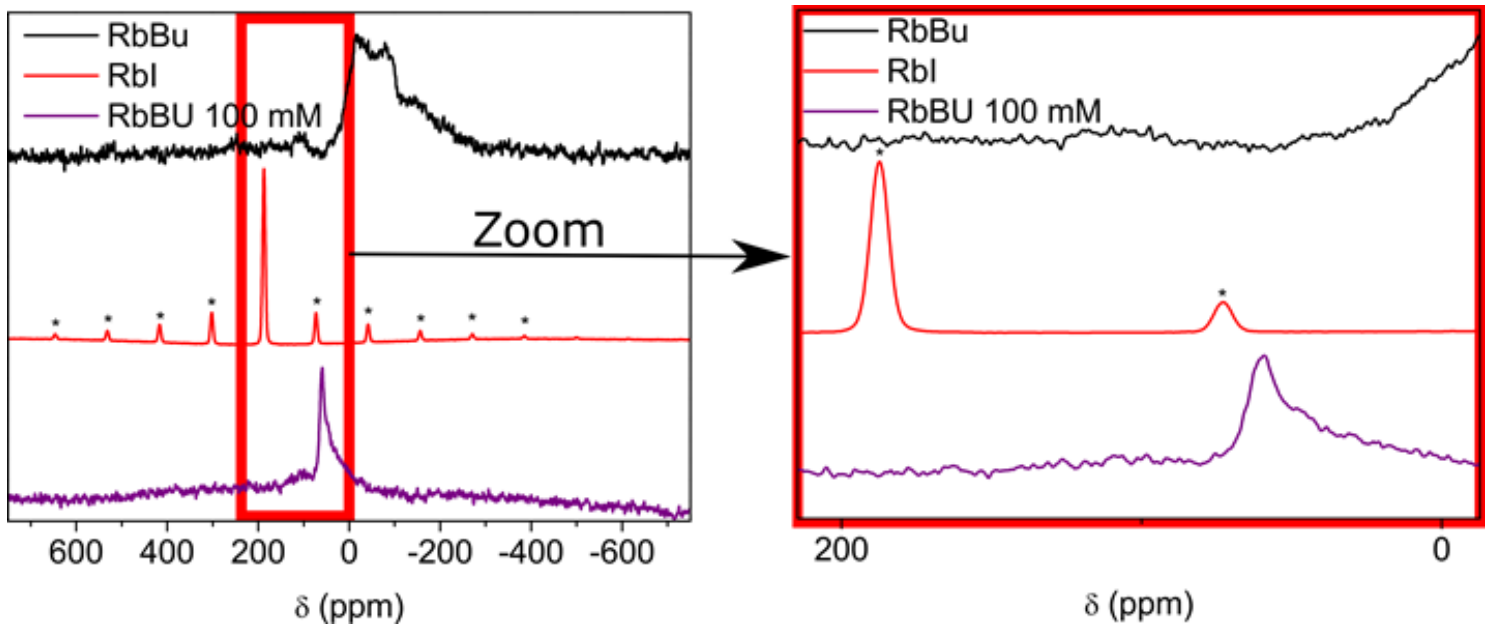

Figure S2. ${ }^{87} \mathrm{Rb}-\mathrm{MAS}-\mathrm{NMR}$ spectra of RbBu (black), RbI (red) and RbBu-100 (purple). 


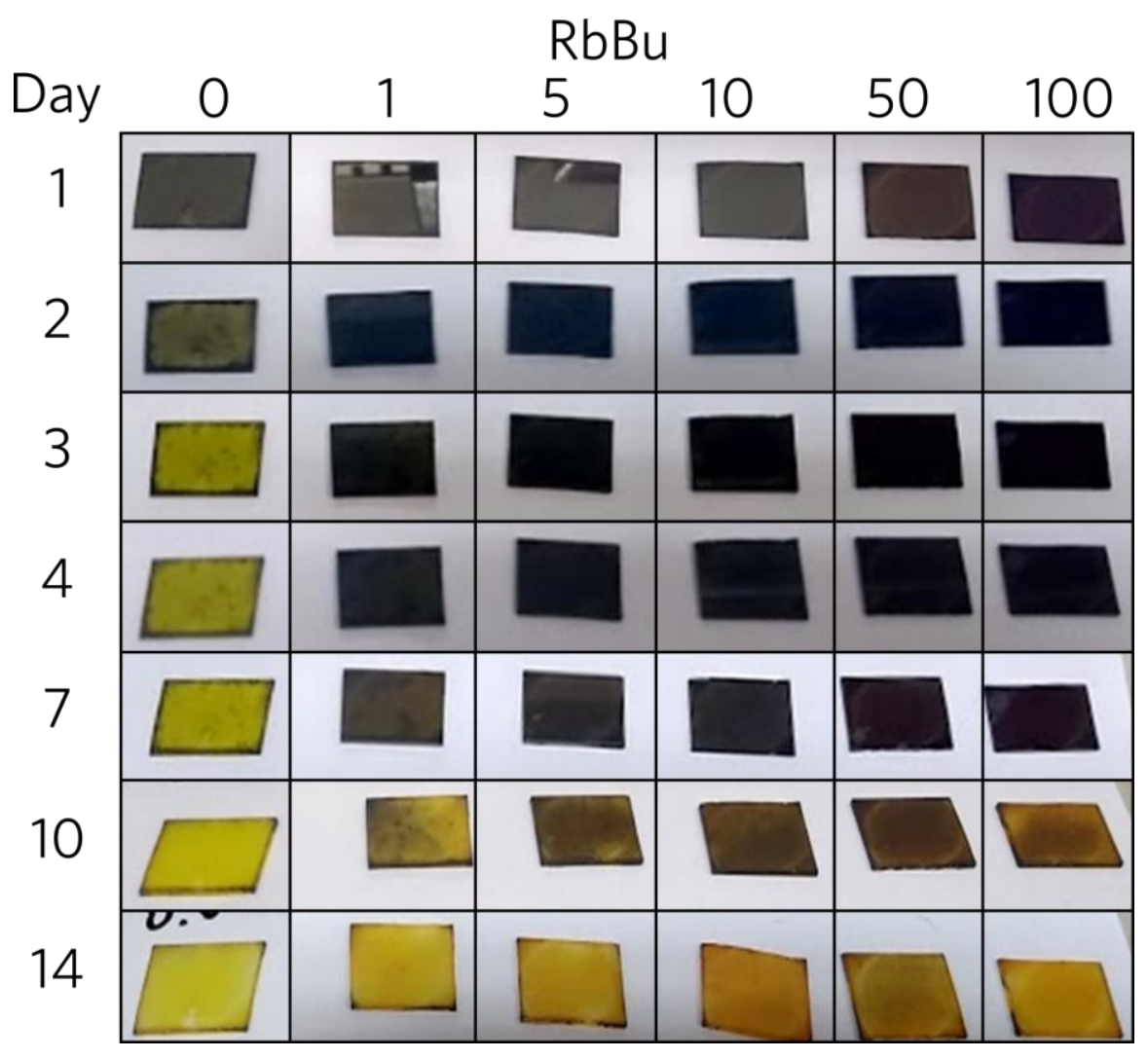

Figure S3: Visual stability test of CsFA perovskite deposited onto glass and exposed to air with relative humidity of $40-60 \%$ for two weeks.

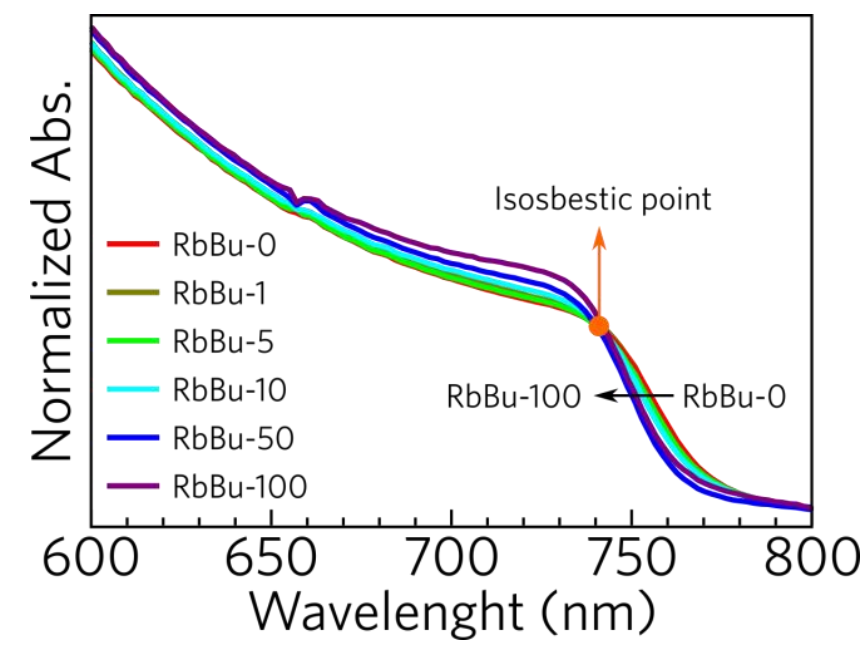

Figure S4: UV-Vis absorption spectra of the perovskite films passivated with $\mathrm{RbBu}$. 


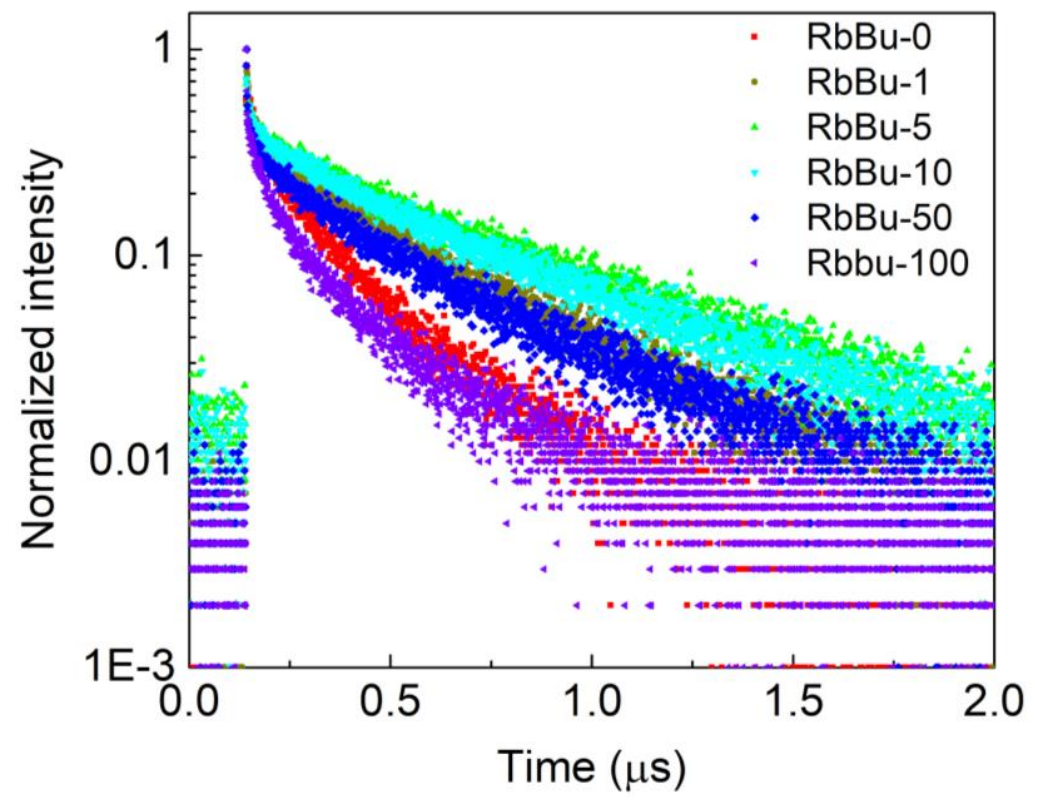

Figure S5. TRPL decays of pristine and surface modified samples by RbBu solutions $\left(\lambda_{\mathrm{exc}}=\right.$ $\left.440 \mathrm{~nm} ; \lambda_{\mathrm{PL}}=760 \mathrm{~nm} ; \mathrm{F}=9.7 \mathrm{~nJ} \mathrm{~cm}{ }^{-2}\right)$.

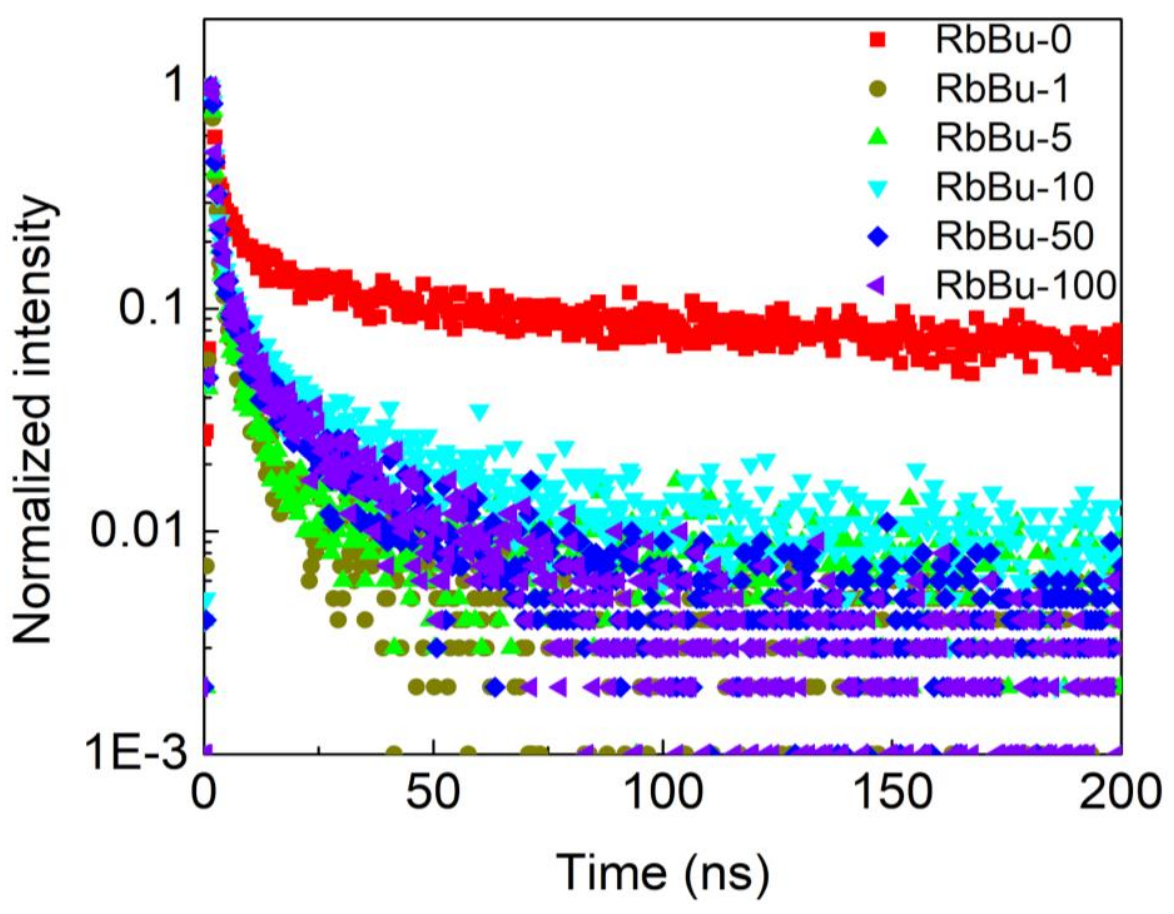

Figure S6. TRPL decays of pristine and surface modified samples by RbBu solutions with Spiro-OMeTAD layer on the top of the films $\left(\lambda_{\mathrm{exc}}=440 \mathrm{~nm} ; \lambda_{\mathrm{PL}}=760 \mathrm{~nm} ; \mathrm{F}=9.7 \mathrm{~nJ} \mathrm{\textrm {cm } ^ { - 2 }}\right)$. 

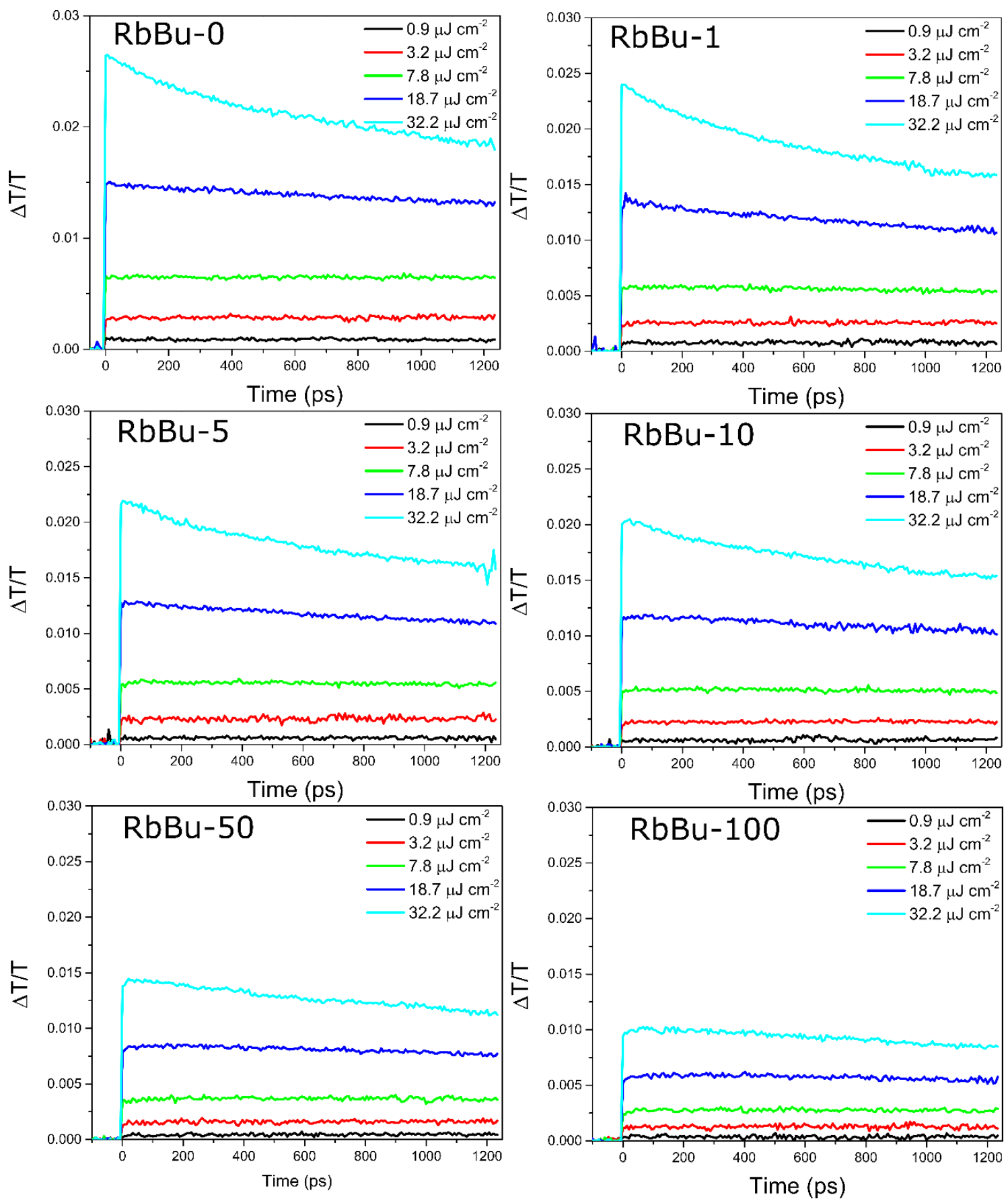

Figure S7. OPTP decays varying the laser fluence for the pristine and surface modified films with $\mathrm{RbBu}$ post passivation additive $\left(\lambda_{\text {pump }}=400 \mathrm{~nm}\right)$. 

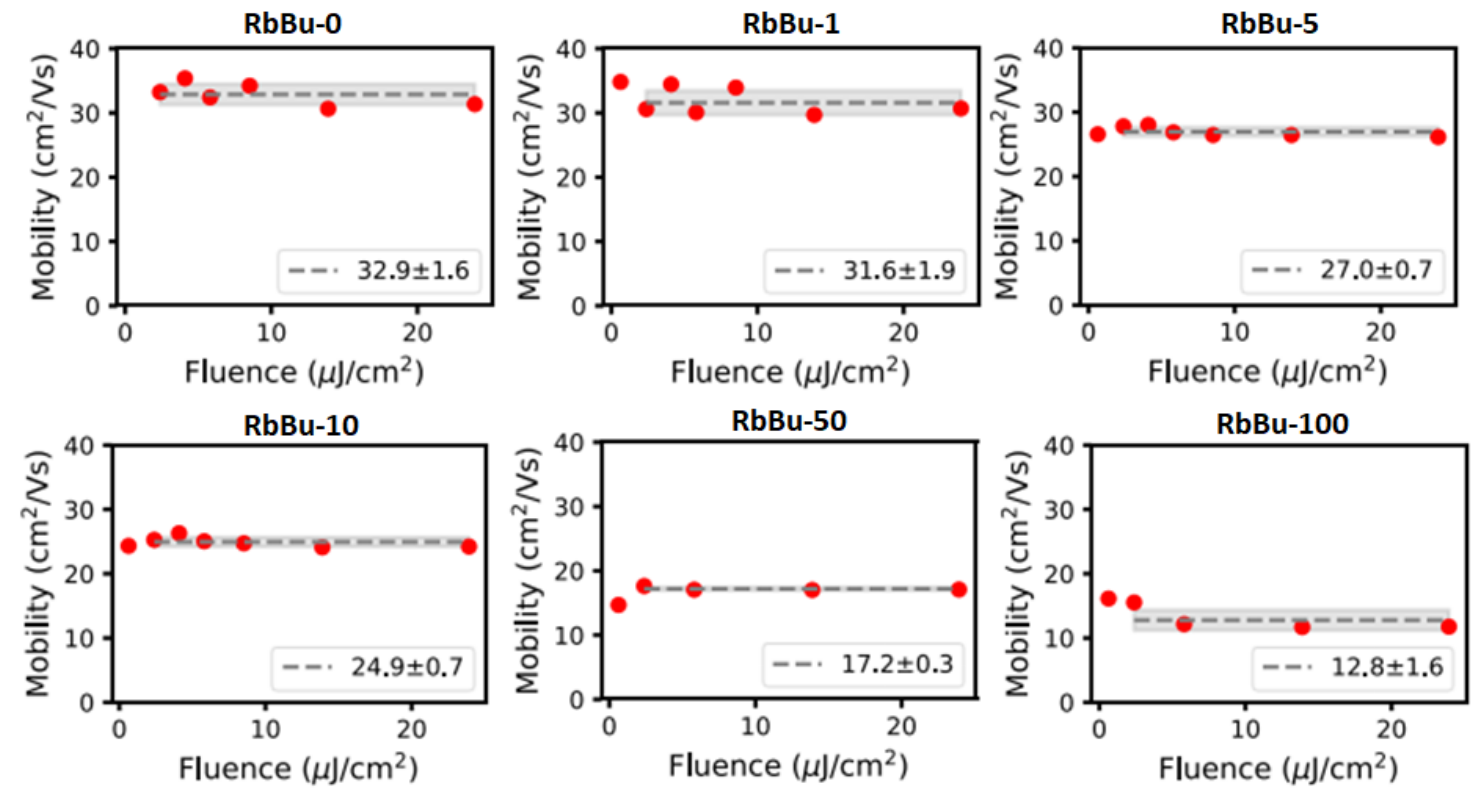

Figure S8. THz charge-carrier mobilities as function of the laser fluence for the pristine and surface modified films with RbBu post passivation additive. 

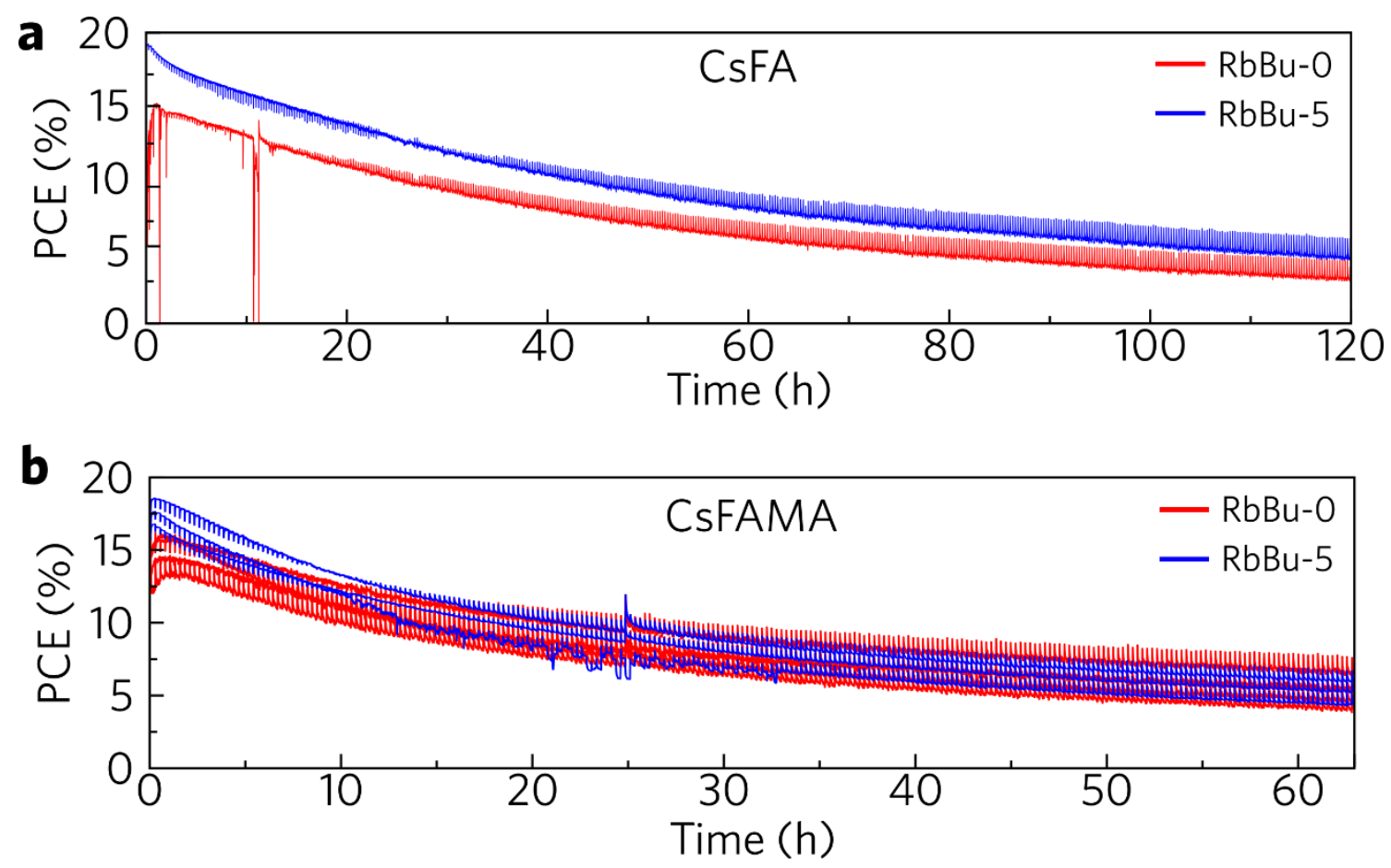

Figure S9: PCE obtained at MPP aging in inert atmosphere $\left(\mathrm{N}_{2}\right)$ and under 1 sun continuous illumination of PSCs with and without RbBu passivation for (a) CsFA and (b) CsFAMA perovskites.

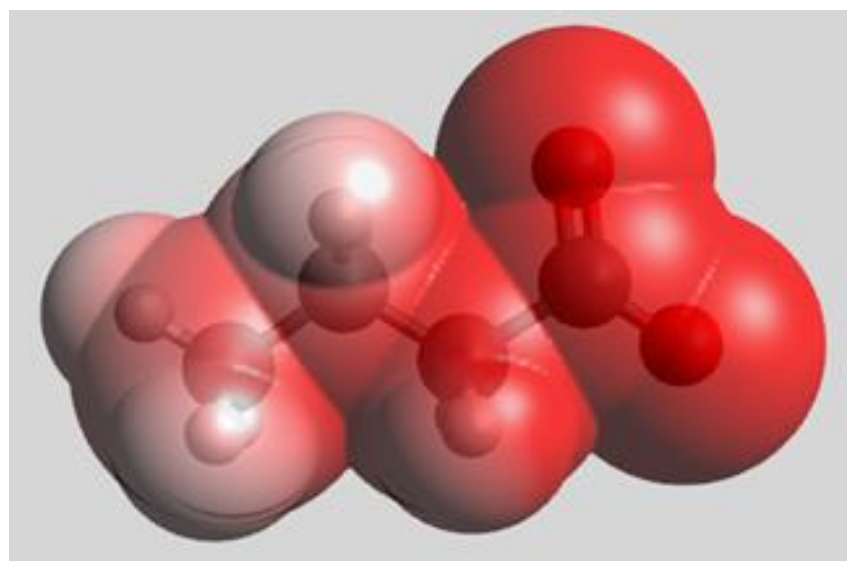

Figure S10: Optimized geometry and electrostatic surface volume of $\mathrm{Bu}^{-}$anion. Increment of red color indicates the negative charge distribution along the molecule. 
Table S1. Resume of the charge-carrier lifetimes $\left(\tau_{\mathrm{S}}\right), \beta_{S}$, first-order rates $\left(k_{l}\right)$ (from TRPL), mobilities (from OPTP) measured at front $\left(\mu_{\mathrm{F}}\right)$ and back $\left(\mu_{\mathrm{B}}\right)$ face orientations, and chargecarrier diffusion lengths $\left(\mathrm{L}_{\mathrm{D}}\right)$ for the post treated perovskites with $\mathrm{RbBu}$ solutions.

\begin{tabular}{cccccccc}
\hline $\begin{array}{c}\mathbf{R b B u} \\
(\mathrm{mM})\end{array}$ & $\tau_{\mathbf{S}}(\mathrm{ns})$ & $\boldsymbol{\beta} \mathbf{S}$ & $\boldsymbol{k}_{\boldsymbol{I}}\left(\mathrm{s}^{-1}\right)$ & $\mathbf{R}^{2}$ & $\boldsymbol{\mu}_{\mathbf{F}}\left(\mathrm{cm}^{2} \mathrm{~V}^{-1} \mathrm{~s}^{-1}\right)$ & $\boldsymbol{\mu}_{\mathbf{B}}\left(\mathrm{cm}^{2} \mathrm{~V}^{-1} \mathrm{~s}^{-1}\right)$ & $\mathbf{L}_{\mathbf{D}}(\mu \mathrm{m})$ \\
\hline $\mathbf{0}$ & 168 & 1 & $5.95 \times 10^{6}$ & 0.963 & 31.9 & 39.1 & 3.69 \\
$\mathbf{1}$ & 185 & 0.706 & $3.82 \times 10^{6}$ & 0.949 & 30.3 & 37.0 & 4.49 \\
$\mathbf{5}$ & 210 & 0.574 & $2.73 \times 10^{6}$ & 0.962 & 26.8 & 36.5 & 5.00 \\
$\mathbf{1 0}$ & 199 & 0.589 & $2.96 \times 10^{6}$ & 0.961 & 24.7 & 37.0 & 4.61 \\
$\mathbf{5 0}$ & 142 & 0.636 & $4.48 \times 10^{6}$ & 0.942 & 17.2 & 35.7 & 3.13 \\
$\mathbf{1 0 0}$ & 134 & 1 & $7.46 \times 10^{6}$ & 0.883 & 12.9 & 33.4 & 2.10 \\
\hline
\end{tabular}


Table S2. Resume of the PSCs parameters.

\begin{tabular}{|c|c|c|c|c|c|c|}
\hline & & $\mathbf{V}_{\text {oc }}(\mathrm{V})$ & $\mathrm{JSC}_{\mathrm{SC}}\left(\mathrm{mA} \mathrm{cm} \mathrm{cm}^{-2}\right)$ & FF & PCE $(\%)$ & MPP (\%) \\
\hline \multirow{2}{*}{ RbBu-0 } & $\mathbf{F}$ & $1.10 \pm 0.01$ & $22.1 \pm 0.2$ & $0.64 \pm 0.02$ & $15.5 \pm 0.7$ & \multirow{2}{*}{$13.9 \pm 1.8$} \\
\hline & B & $1.14 \pm 0.02$ & $22.0 \pm 0.2$ & $0.67 \pm 0.03$ & $16.9 \pm 0.8$ & \\
\hline \multirow{2}{*}{ RbBu-1 } & $\mathbf{F}$ & $1.14 \pm 0.01$ & $22.2 \pm 0.1$ & $0.68 \pm 0.01$ & $17.3 \pm 0.2$ & \multirow{2}{*}{$16.8 \pm 0.6$} \\
\hline & B & $1.16 \pm 0.01$ & $22.1 \pm 0.2$ & $0.69 \pm 0.01$ & $17.7 \pm 0.2$ & \\
\hline \multirow{2}{*}{ RbBu-5 } & $\mathbf{F}$ & $1.14 \pm 0.01$ & $22.0 \pm 0.1$ & $0.71 \pm 0.01$ & $17.7 \pm 0.2$ & \multirow{2}{*}{$17.2 \pm 0.2$} \\
\hline & B & $1.15 \pm 0.01$ & $22.0 \pm 0.2$ & $0.69 \pm 0.01$ & $17.6 \pm 0.3$ & \\
\hline \multirow{2}{*}{ RbBu-10 } & $\mathbf{F}$ & $1.12 \pm 0.01$ & $22.3 \pm 0.1$ & $0.65 \pm 0.02$ & $16.1 \pm 0.8$ & \multirow{2}{*}{$15.5 \pm 1.1$} \\
\hline & B & $1.15 \pm 0.01$ & $22.1 \pm 0.2$ & $0.67 \pm 0.01$ & $17.0 \pm 0.5$ & \\
\hline \multirow{2}{*}{ RbBu-50 } & $\mathbf{F}$ & $1.14 \pm 0.01$ & $22.0 \pm 0.2$ & $0.65 \pm 0.02$ & $16.5 \pm 0.6$ & \multirow{2}{*}{$15.9 \pm 0.3$} \\
\hline & B & $1.17 \pm 0.01$ & $21.9 \pm 0.2$ & $0.68 \pm 0.02$ & $17.3 \pm 0.6$ & \\
\hline \multirow{2}{*}{ RbBu-100 } & $\mathbf{F}$ & $1.09 \pm 0.02$ & $21.8 \pm 0.1$ & $0.59 \pm 0.03$ & $14.0 \pm 0.9$ & \multirow{2}{*}{$12.6 \pm 1.3$} \\
\hline & B & $1.11 \pm 0.03$ & $21.4 \pm 0.4$ & $0.61 \pm 0.04$ & $14.5 \pm 1.5$ & \\
\hline
\end{tabular}

\section{Supporting Text 1}

We performed solid-state magic-angle nuclear magnetic resonance (MAS-NMR) of ${ }^{87} \mathrm{Rb}$ (Figures S2). These experiments were done only for the most concentrated sample (RbBu-100). In the ${ }^{87} \mathrm{Rb}-\mathrm{MAS}-\mathrm{NMR}$ spectra, a clear ${ }^{87} \mathrm{Rb}$ resonance peak at $\delta=63$ and 59 ppm is observed, most likely related to the $\delta$ - $\mathrm{RbPb}\left(\mathrm{Br}_{\mathrm{x}} \mathrm{I}_{1-\mathrm{x}}\right)_{3}$ non-perovskite phases, with a similar spectral shape in comparison with a previous work published by Kubicki et al. $2017 .^{8}$ A discreet large signal at $46 \mathrm{ppm}$ is probably related to the presence of $\mathrm{Rb}^{+}$cations passivating the surface defects of A-site or interstitial sites on the surface of LHP grains. Also, no formation of the $\operatorname{RbI}(\delta=187$ and $73 \mathrm{ppm})$ and $\operatorname{RbBr}(\delta=150 \mathrm{ppm}),{ }^{8}$ or vestiges of $\mathrm{RbBu}$ (large resonance at $\delta<0 \mathrm{ppm}$, due to its amorphous nature; see Figure S2), can be observed in the ${ }^{87}$ Rb-MAS-NMR spectra. 


\section{Supporting Text 2}

The total charge-carrier recombination dynamics in LHPs can be obtained by a thirdorder rate equation:

$$
\frac{d n(t)}{d t}=-k_{3} n^{3}-k_{2} n^{2}-k_{1} n
$$

where $n$ is the charge-carrier density, $t$ is the time, $k_{l}$ is the first-order (monomolecular trapassisted), $k_{2}$ is the second-order (bimolecular band-to-band), and $k_{3}$ is the third-order (Auger) recombination rates, respectively. The contribution of the high-order charge-carrier dynamics can be neglected in a time-correlated single photon counting (TCSPC) experiment at low-fluence regimes $\left(\mathrm{F}=9.7 \mathrm{~nJ} \mathrm{~cm}^{-2}\right) .{ }^{9}$ The monoexponential decay common function does not adjust the TRPL decays due to the disorder and aleatorily of the perovskites films and processing conditions. ${ }^{10}$ Therefore, a stretched exponential decay function were used in order to extract the charge-carrier lifetimes, using the following equation:

$$
I(t)=I_{0} e^{-\left(\frac{t}{\tau_{S}}\right)^{\beta} S}
$$

where $I(\mathrm{t})$ is the time-dependent intensity, $I_{0}$ is the intensity at the "zero" time, $\tau_{\mathrm{S}}$ is the charge-carrier lifetime, and $\beta_{S}$ is the stretching factor, which varies between $0.5<\beta_{S} \leq 1$ and is directly related to the LHPs thin-film disorder. As a consequence of the stretched exponential model, the first-order recombination rate is expressed by equation $3:^{11,12}$

$$
k_{1}=\frac{\beta_{S}}{\tau_{S}}\left(\frac{t}{\tau_{S}}\right)^{\beta_{S}-1}
$$




\section{Supporting text 3}

In order to verify in more details, the chemical composition on the perovskite surface after passivation, we carried out X-Ray photoelectron spectroscopy (XPS). Figure S11 displays the $\mathrm{Rb} 3 \mathrm{~d}$ XPS for $\mathrm{RbBu}$ and perovskites. The perovskite film without $\mathrm{RbBu}$ does not show any $\mathrm{Rb} 3 \mathrm{~d}$ peak, as expected, and the same for samples $\mathrm{RbBu}-1$ and $\mathrm{RbBu}-5$ due to small amounts of $\mathrm{Rb}$. For sample $\mathrm{RbBu}-10$ small peaks from $\mathrm{Rb} 3 \mathrm{~d}\left(3 \mathrm{~d}_{3 / 2}=111.5 \mathrm{eV}\right.$ and $3 \mathrm{~d}_{5 / 2}=109.9 \mathrm{eV}$ ) were detected. We attributed these peaks to $\mathrm{Rb}^{+}$passivating halide defects located near grain boundaries. For $\mathrm{RbBu}-50$ and $\mathrm{RbBu}-100$ new peaks at higher energy (112.2 and $110.8 \mathrm{eV})$ emerged. These new peaks are attributed to $\delta-\mathrm{RbPb}\left(\mathrm{Br}_{\mathrm{x}} \mathrm{I}_{1-\mathrm{x}}\right)_{3}$ formed by the higher amount of $\mathrm{Rb}^{+}$introduced by the passivation consistent with XRD pattern. 


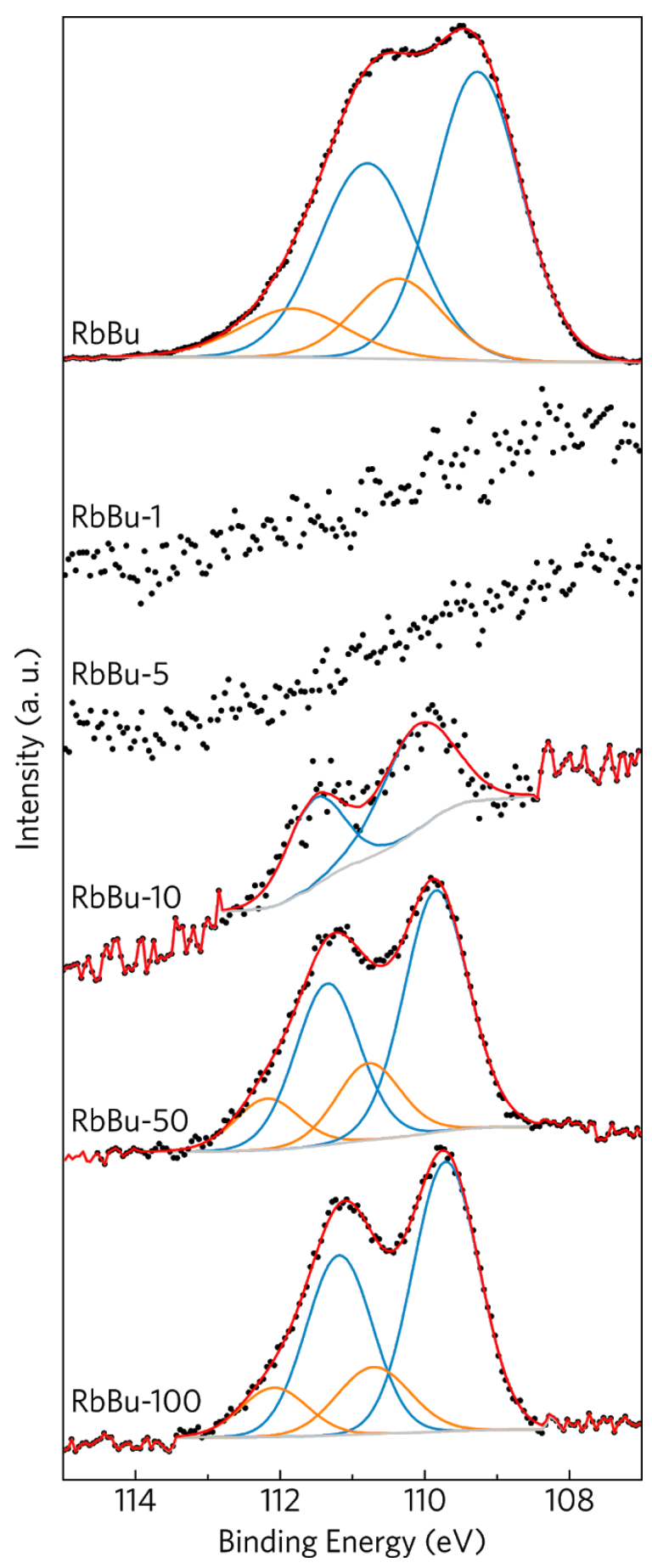

Figure S11: High resolution XPS spectra for RbBu and perovskite films with passivation.

\section{References}

(1) Wehrenfennig, C.; Eperon, G. E.; Johnston, M. B.; Snaith, H. J.; Herz, L. M. High Charge Carrier Mobilities and Lifetimes in Organolead Trihalide Perovskites. $A d v$. Mater. 2014, 26 (10), 1584-1589. 
(2) Becke, A. D. Density-Functional Thermochemistry. III. The Role of Exact Exchange. J. Chem. Phys. 1993, 98 (7), 5648-5652.

(3) Krishnan, R.; Binkley, J. S.; Seeger, R.; Pople, J. A. Self-Consistent Molecular Orbital Methods. XX. A Basis Set for Correlated Wave Functions. J. Chem. Phys. 1980, 72 (1), 650-654.

(4) Clark, T.; Chandrasekhar, J.; Spitznagel, G. W.; Schleyer, P. V. R. Efficient Diffuse Function-augmented Basis Sets for Anion Calculations. III. The 3-21+G Basis Set for First-row Elements, Li-F. J. Comput. Chem. 1983, 4 (3), 294-301.

(5) Frisch, M. J.; Pople, J. A.; Binkley, J. S. Self-Consistent Molecular Orbital Methods 25. Supplementary Functions for Gaussian Basis Sets. J. Chem. Phys. 1984, 80 (7), $3265-3269$.

(6) Neese, F. Software Update: The ORCA Program System, Version 4.0. Wiley Interdiscip. Rev. Comput. Mol. Sci. 2018, 8 (1), 1-6.

(7) Hanwell, M. D.; Curtis, D. E.; Lonie, D. C.; Vandermeersch, T.; Zurek, E.; Hutchison, G. R. Avogadro: An Advanced Semantic Chemical Editor, Visualization, and Analysis Platform. Adv. Math. (N. Y). 2012, 4-17.

(8) Kubicki, D. J.; Prochowicz, D.; Hofstetter, A.; Zakeeruddin, S. M.; Grätzel, M.; Emsley, L. Phase Segregation in Cs-, Rb- and K-Doped Mixed-Cation (MA)x(FA)1XPbI3 Hybrid Perovskites from Solid-State NMR. J. Am. Chem. Soc. 2017, 139 (40), $14173-14180$.

(9) Johnston, M. B.; Herz, L. M. Hybrid Perovskites for Photovoltaics: Charge-Carrier Recombination, Diffusion, and Radiative Efficiencies. Acc. Chem. Res. 2016, 49 (1), $146-154$.

(10) Dequilettes, D. W.; Frohna, K.; Emin, D.; Kirchartz, T.; Bulovic, V.; Ginger, D. S.; Stranks, S. D. Charge-Carrier Recombination in Halide Perovskites. Chem. Rev. 2019, 
$119(20), 11007-11019$.

(11) Berberan-Santos, M. N.; Bodunov, E. N.; Valeur, B. Mathematical Functions for the Analysis of Luminescence Decays with Underlying Distributions 1. Kohlrausch Decay Function (Stretched Exponential). Chem. Phys. 2005, 315 (1-2), 171-182.

(12) Stranks, S. D.; Eperon, G. E.; Grancini, G.; Menelaou, C.; Alcocer, M. J. P.; Leijtens, T.; Herz, L. M.; Petrozza, A.; Snaith, H. J. Electron-Hole Diffusion Lengths Exceeding Trihalide Perovskite Absorber. Science (80-. ). 2013, 342 (October), 341-344. 